\title{
Development of Electric Urban Mobility: Comparative Research and Preliminary Survey
}

\author{
Francesco Asdrubali 1*, Stefano Carrese ${ }^{1}$, Sergio Maria Patella ${ }^{1}$, Leonardo Sabatini ${ }^{1}$ \\ ${ }^{1}$ Department of Engineering, Roma Tre University, Rome, ITALY
}

*Corresponding Author: francesco.asdrubali@uniroma3.it

Citation: Asdrubali, F., Carrese, S., Patella, S. M. and Sabatini, L. (2018). Development of Electric Urban Mobility: Comparative Research and Preliminary Survey. European Journal of Sustainable Development Research, 2(3), 32. https://doi.org/10.20897/ejosdr/89694

Published: July 9, 2018

\begin{abstract}
The growing concerns about greenhouse gas emissions at the international level have shifted American and European policies to invest in sustainable mobility. Although substantial steps have been made in recent years, electric mobility is still not an integral part of today's transport systems. The aim of the study is to provide a comparative overview of the Italian approach to electric mobility and to define future approaches that could be used. Our research used a web-based survey, applying standard statistical methods to data processing. From these results the authors defined the playing field of the current results, and the variables for the future development of electric urban mobility. This analysis has shown a gap in the knowledge of the results reached in recent years by consumers and displayed an interest in new types of ecological fuels. Regarding Italian policies, it is clear that major efforts in economic and infrastructural facilitations are needed. In addition, this analysis can be used in the future to check for any developments and to generate a larger dataset with other partners.
\end{abstract}

Keywords: urban mobility, electric vehicles, travelers behavior

\section{INTRODUCTION}

Sustainable mobility has been steadily developing over the past decades; for example, in 1997, following the merger between Honda and Toyota in Japan, the first hybrid vehicle, "Prius I" was created (Dijk et al., 2013). Since then, it has been a race to develop new technologies, increasing the supply and presence of low environmental impact vehicles on the market.

The technological development achieved in this last decade was not only pushed by car companies, but also from active political support. The publications of "The White Paper on Transport" and the "American Recovery and Reinvestment Act" led to the development of alternative fuels and better technologies for sustainable mobility (Leurent et al., 2011). In addition, several States focused their attention on the "decarbonization" of transportation, not only for environmental reasons, but also for national energy security, limiting dependence on oil imports. In particular, the role of policy in electric mobility has been crucial in extra-European countries, such as Norway, world leader in the use of electric vehicles and Oslo, Electric Vehicle (EV) capital of the world (EVUE, 2015).

This work highlights the impacts of technical aspects, policy and incentives, pro-environmental behavior as affecting travelers propension to urban electric mobility.

What motivates people to adopt pro-environmental attitudes has become a central problem of socioenvironmental research (Saunders, 2003; Stern, 2005). Several studies have shown that the mode choice is a good 
context to observe the role of normative in relation to pro-environmental behavior. Hunecke et al. (2001) have highlighted a significant association between norms and mode choice.

This study was carried out within the EU funded project "eMobilita" (Horizon 2020, program "Marie Skłodowska-Curie Actions"). In particular, Roma Tre University, in synergy with other European Academic Partners, intends to propose concrete solutions to integrate urban electric mobility and sharing mobility (Carrese et al., 2017).

A research survey was used to support this study, drawn up with the Revealed Preference (RP) and Stated Preferences (SP) techniques.

The web-based survey was submitted to randomly-selected Italian respondents and, at the end of the diffusion period, 159 responses were obtained. Responses of the statistical sample have shown a reduction of interests in LPG/methane vehicles and an increase of interest in electric cars or vehicles powered by innovative technologies, such as hydrogen or biofuels. To interpret the results, a multivariate analysis, such as Factor Analysis, was used to define the most significant variables for the diffusion of electric mobility.

This research presents a comparative analysis among different European countries about the market penetration of EVs. The authors argue that the introduction of electric vehicles is a direct consequence of different policies and incentives implemented by governments. In order to better understand the factors that could have led to a switch to EV, this study uses a survey and a statistical analysis.

The main focus of this research is to select, through standard statistical models, the most relevant factors that affect the diffusion of sustainable mobility in urban areas. This preliminary survey provided the essential elements for the design of a synthetic questionnaire.

\section{COMPARED STATE OF THE ART OF URBAN ELECTRIC MOBILITY}

\section{Market Data}

In order to spread electric mobility, it is necessary to educate the public on the benefits of this technology. For instance, the aesthetic design of the Toyota Prius began attracting drivers in 2010 (Burgess et al., 2013).

Today, the European Commission has recognized the presence of $56 \mathrm{M} 1^{1}$ Battery Electric Vehicles (BEVs) worldwide. However, removing vehicles that have left the market or were prototypes, there are only 27 commercial BEVs listed as of September 2017 (European Alternative Fuels Observatory, 2017)

In 2015, the number of electric cars in the world reached 1.26 million, a 100x growth from 2010. The market shares of electric cars exceed 1\% in Norway, the Netherlands, Sweden, Denmark, France, China and the United Kingdom. In these countries almost $40 \%$ of EVs was represented by BEVs (IEA, 2016).

In the European case, only six countries accounted for about $90 \%$ of all electric vehicles sales, BEVs and Plugin Hybrids Electric Vehicles (PHEVs): Netherlands, United Kingdom, Germany, France, Sweden and Denmark. In particular, compared to 2014, sales in 2015 doubled and reached 150,000 (EEA, 2016). The latest data from 2016 showed a further growth in sales, bringing the total number of vehicles (BEVs and PHEVs) circulating in Europe to more than 500,000 (Transport \& Environment, 2016)

Analyzing data from 2015 of EU-28 countries, France has had the highest number of BEVs sales with more than 17,650 vehicles, followed by Germany, with more than 12,350 vehicles, and the UK, with more than 9,900 vehicles. The largest number of PHEVs sales was recorded in the Netherlands, with over 41,000 vehicles, and in the United Kingdom, with more than 18,800 vehicles. Nonetheless, the leader for the sales of electric vehicles is Norway, a non-EU country that in 2015 summed up to almost $22.5 \%$ of the total. This percentage represents 34,000 electric vehicles, of which $77 \%$ BEVs. It is important to underline that the European sale of hybrid vehicles (not Plug-in), is not easily available from official EU statistics, since some Member States categorized these vehicles as simple internal combustion vehicles (EEA, 2016).

\section{Market Data (Italian Case)}

For what regards Italy, the electric vehicle market gradually increased: in 2016, considering BEVs and PHEVs, Rome represented the city with the highest number of registrations (19.2\%), followed by Milan (10.8\%), Bolzano and Trento $(6 \%)$. The data shows citizens' sensitivity when purchasing a vehicle, but in practical terms, only 3,500 vehicles were purchased in 2016.

From the analysis of the registrations of September 2017 of the Unione Nazionale Rappresentanti Autoveicoli Esteri (UNRAE) database, in 2017 hybrid vehicles accounted for 3.1\% of the Italian car market, while battery electric vehicles $0.1 \%$.

\footnotetext{
${ }^{1} \mathrm{M} 1$ vehicles are defined as vehicles intended for the carriage of passengers and comprising no more than eight seats in addition to the driver's seat.
} 
European Journal of Sustainable Development Research, 2(3), 32

Table 1. Battery Electric Vehicles and Hybrid Vehicles registration in Italy (UNRAE data)

\begin{tabular}{ccccc}
\hline Year & N. of Electric Vehicles & Percentage change & N. of Hybrid Vehicles & Percentage change \\
\hline 2013 & 847 & -- & 14,550 & -- \\
\hline 2014 & 1,110 & $31.1 \%$ & 20,712 & $42.4 \%$ \\
\hline 2015 & 1,460 & $31.5 \%$ & 26,117 & 38,874 \\
\hline 2016 & 1,403 & $-3.9 \%$ & 54,969 \\
\hline Jan.-Oct./2017 & 1,645 & $17.2 \%$ & $48.8 \%$ & $41.4 \%$ \\
\hline
\end{tabular}

To provide a complete overview of the Italian case, the registrations of BEVs and hybrid vehicles are reported from January 2013, the first useful period available from the UNRAE database.

Analyzing the percentage variation of values concerning the sales of BEVs in Table 1, encouraging results emerge in terms of diffusion of sustainable mobility.

These data do not account for public transportation vehicles such as buses. According to a report of the Italian association of road transport companies (ANAV), the average age of Italian buses for local public transport services accounts to about 12 years, well above the 7-year average of most European countries. Due to the economic constraints on transport companies, ecological vehicles are still not widely used but Beltran et al. (2009) stated that it is possible to optimize their use with processes of network design and by creating "green lines".

\section{Policy and Incentives}

Considering the mounting dangers of climate change, international governments have sought to develop and set policies to solve the problem of greenhouse gas emissions, focusing on fixing the transportation sector. At the end of 2010, the European Commission issued a document entitled "European strategy on clean and energy efficient vehicles" with the aim of becoming a leader in the sales and promotion of electric vehicles and related technologies. Presently, these ambitious targets have not been yet reached, indeed in 2015 China has become the leader in electric vehicles sales, placing the European Union in second position (Transport \& Environment, 2016). Finally, the United States wanted to focus on international industrial cooperation with China and Japan, respectively with programs U.S-China Electric Vebicles Initiative and Japan-U.S. Clean Energy Technologies Action Plan. Leurent et al. (2011) affirmed that the goal of electric mobility is to reduce the environmental impact of pollution caused by transportation vehicles. This objective can only be achieved if there is an integration between the electric vehicles and a parallel production of charging network powered by renewable energies. A concrete response to reduce the alarming levels of urban emissions is provided by Carrese et al. (2013). They claim that, in the short term, the integration of electric and hybrid vehicles with public transportation could bring some interesting results. In support of this thesis, they studied the reduction of emissions with the role of the new Intelligent Transportation Systems (ITS) in Rome.

In 2011, the European Commission published in the White Paper on Transport the "Roadmap to a Single European Transport Area - Towards a competitive and resource efficient transport system". This document promotes sustainable mobility with a $60 \%$ emission reduction target by 2050 . In order to achieve it, it is necessary on one hand to reduce European dependence on oil, and on the other to simultaneously support the development and diffusion of new ecological fuels and propulsion systems. In the context of "sustainable transport" the following interventions are required. For transports made by trucks with distances over $300 \mathrm{~km}$ it is necessary to transfer the goods by ships or trains, where $30 \%$ will have to be done by 2030 and $50 \%$ by 2050 .

Furthermore, it is necessary to analyze Norway, the world leader in the use of electric vehicles, and Oslo as the electric vehicles' (EVs') capital of the world, since it has the highest density of EVs. These results of behavioral change of consumers have been achieved through joint projects with various stakeholders. In particular, over the last 20 years, Norway has set up a framework to promote the use of electric vehicles and to support electric vehicle manufacturers in the territory. A key role has been played by the Norstart Association, which has been an intermediary between the lobby of political parties and electric vehicles industries.

The following are some actions that have led to the success of the Norwegian policies (EVUE, 2015):

- Drive for free on toll roads

- No VAT $(25 \%)$ on new vehicles

- No "first-time registration fee" on new vehicles

- Permission to drive in reserved lanes to public transport services (bus and cab)

- Free parking in public spaces

- No charge for the EVs on local ferries

This example shows how political support, reinforced by economic incentives and investment in infrastructure, plays a pivotal role in shifting consumer behavior. It is obvious that in the long term these strategies lose effectiveness, so it is necessary to progressively eliminate them. This step is required as the policy framework needs to evolve and consider wider aspects, such as the potential impact of a reduction in national revenues from the 
fossil fuel taxes (IEA, 2016). This thesis was indeed confirmed by Massiani (2015), who conducted a study on the development of EVs in Germany.

\section{Policy and Incentives (Italian Case)}

Nonetheless, in Italy there are no incentives for private citizens to purchase an electric vehicle or ecological vehicle, such as LPG or methane. Currently, the only economic incentive is the removal of the car (road) tax for EVs, paid based on the horsepower of the endothermic engine for hybrid vehicles. Different conditions are defined for VTA users, who benefited from the super-amortization tax incentives in 2017. Further advantages are defined by Municipalities, such as access to restricted areas (LTZ - limited traffic rone) and free parking in toll parking lots delimited by blue lines. Only the residents of the autonomous province of South Tyrol are provided with economic incentives to purchase EVs, indeed citizens and VTA users receive a $€ 4,000$ grant, half of which provided by the province and half by retailers.

Italy has heavily invested in Natural Gas Vehicles (NGVs) in the past few years. The presence of LPG vehicles was $3.81 \%$ in 2005 and reached $7.76 \%$ by the end of December 2014, recording a total increase of $117.52 \%$ in about 10 years. Specifically, this latter percentage is equivalent to 2,875,788 vehicles, of which 833,668 methane and 2,042,120 in LPG. This is well above the average European levels of 1.5\%. Recently this trend has changed due to the fact that part of this result was attributable to the fall in oil Brent price, getting below $\$ 50$ a barrel.

Looking forward, Italy has decided to focus on investing in hydrogen. The Italian Government has included this last project in its strategic plan, and by 2025 it will have to ensure an adequate network of supply stations throughout the country. In addition, a legal act published in the Official Gazette of the Italian Republic in 2017, foresees the increase of the maximum operating pressure of the hydrogen supply pumps, from the current 350 Bar up to 700 Bar, allowing refueling to be completed in 3 minutes (Eideh, 2017).

\section{Environmental Benefits and Impacts}

The benefits of BEVs are zero local emissions, high efficiency and low noise. However, energy consumption and efficiency depend on different factors such as resistance to motion, driving style, and vehicle size.

The European Environmental Agency (EEA) has studied the environmental impacts of electric mobility, and, if in $205080 \%$ of the vehicles will be electric so to satisfy the demand of electricity, it will be necessary to generate an additional $150 \mathrm{GW}$ of electricity. Although a significantly larger amount of electricity production is required in the energy sector, more EVs will lead to a reduction of greenhouse gases $\left(\mathrm{CO}_{2}\right)$ and local atmospheric pollutants (NOx, $\mathrm{SO}_{2}, \mathrm{PM}$ ) in the transportation sector (Asdrubali et al., 2015). However, the problem concerning the source of production remains. Thus, as the EEA affirmed, if the demand for additional electricity was provided by an energy mix, including a significant amount of renewable energies, the expected scenario of 2050, in terms of future greenhouse gas emissions (GHG) and other atmospheric pollutants (NOx and PM), would be still lower, producing a clear overall net environmental benefit (Eideh, 2017). Maintaining the assumption that by 2050 the European fleet will constitute $80 \%$ of all electric vehicles, then will be a reduction in greenhouse gas emissions of 255 million tons of $\mathrm{CO}_{2}$ compared to the EU Reference Scenario 2013.

The main concern, with regard to the production of electric vehicles, is the scarcity of the materials with which some components, including the magnets of electric motors and batteries, are produced. Examples of the rare earth elements used in magnets and batteries are neodymium, dysprosium samarium, cobalt, lanthanum and nickel. In the future, a "closed loop" recycling system will be necessary. Despite concerns over production efficiency, the reduced emissions achieved during the life of an electric vehicle are considered superior to the environmental effects of production and end-of-life phases. Therefore, electric vehicles significantly reduce the negative effects of emissions from internal combustion vehicles, provided that electricity comes from renewable sources (EEA, 2016).

As far as further environmental impacts, the ARTEMIS tool (a result of a European Consortium coordinated by the European Commission's Joint Research Center) was used to track the pollutant emissions and energy consumption in the transport sector. The database consists of measurements of different vehicles categories and moreover, this tool can be applied on different scales, especially for local estimates (André et al., 2009).

In order to simulate the influence of electric vehicles in terms of $\mathrm{CO}_{2}$ emissions, it is possible to use the computer model VECTOR21. In the analysis, the purchase decision of customers is modelled to obtain future market share of propulsion technologies and fuels, considering in the model relevant influencing factors such as consumption, energy prices, or taxation (Mock et al., 2009).

\section{EMOBILITA PROJECT}

The eMobilita project is funded by the European Commission through the Marie Skłodowska-Curie (MSCA) program for Research and Innovation - Horizon 2020. Notably, the project is published as H2020-MSCA 
eMobilita-Electromobility in urban transport: a multi-dimensional innovation (socio-economics and environmental effects).

The coordinator of the project is the University of National and World Economy (UNWE) of Bulgaria, which, together with industrial and academic partners, aims to study the conditions, prerequisites, and incentives for the urban integration of the electric mobility and elaboration of a roadmap for its development. In particular, the project has the ambition to explore the experience of the European countries in the integration of electromobility and summarize the related direct/indirect multi-dimensional effects (social, economic and environmental).

The Academic Network is made up of the following European Universities:

- UNIROMA3, Università degli Studi Roma Tre - ITALY

- UNWE, University of National and World Economy - BULGARIA

- EUBA, Ekonomická Univerzita V Bratislave - SLOVAKIA

- AUTH, Aristotle University of Thessaloniki - GREECE

The network of organizations and associations is composed of:

- EFFEBI, Finance \& Banking - Associazione per lo sviluppo organizzativo e delle risorse umane (Association) - ITALY

- EVIC, Industrialen Klaster Elektromobili (Organization) - BULGARIA

- SEVA, Slovenská asociácia pre Elektromobilitu (Association) - SLOVAKIA

The duration of the eMobilita project spans over 36 months starting from April 2016. Academic and nonacademic institutions used a Work Package Model (WP) to guarantee a reliable planning and effective management of the following sectors: fieldwork research, analysis and evaluation of empirical data, electro mobility roadmap, knowledge sharing, dissemination, exploitation, communication and management.

UNIROMA3 and EVIC are leaders in "Knowledge Sharing" WP with the objective to ensure favorable conditions of research and innovation in the field of electric mobility. Moreover, the researchers want to generate increased sharing of information between partners through networking activities and develop new inputs of study to produce scientific deliverables for the integration of electric mobility in urban transport.

\section{Description of the Project}

The surveys, elaborated by the Aristotle University of Thessaloniki (Greece), were addressed to respondents of the following types: Citizens, Public Authorities, and Industries. At this stage of the project, research focused on "Citizens" respondents.

Since the eMobilita project is made up of a European partnership, Roma Tre University has decided to focus its attention on the Italian sample and carry out a comparative analysis considering samples from other states. In addition, the Bulgarian and Slovak Universities will provide a detailed situation of Eastern Europe. The goal is to compare the results between the four Universities, generating a single database to describe the behavioral approach of the statistical sample of users, assuming it is representative of the European phenomenon.

\section{Survey}

The authors developed a web-based survey that was conducted for a length of a month and a half (23/07/2017 - 11/09/2017) at the end of which 159 responses were obtained. This survey was based on the hypothesis that respondents increased their knowledge of the new technology during the compilation of the survey. This provides indeed, besides the questions, detailed explications on technologies and technical information regarding electric vehicles, including the support of images of car models and charging stations and also preparatory guides. In fact, it was observed that consumer perceptions varied while gaining greater exposure to new technologies (Axsen, et al. 2009).

The survey consisted of 33 questions divided into five sections: Introduction to the project, Transportation, Charging time and State subsidies, Charging units and costs, and General information. These issues, related to electric mobility and user behavior toward conventional and eco-friendly vehicles, were developed through Revealed Preference (RP) and Stated Preference (SP) techniques (Bateman et al., 2002).

Interviewees were asked to express their level of use, consensus, and importance in relation to some proposed scenarios.

\section{RESULTS AND DISCUSSION}

In order to carry out statistical analyses of the results obtained, an attitude measurement technique, such as the Likert scale, was used in the data processing phase, with values between 1 and 5.

As Table 2 shows, the sample is 'high-educated' since $88 \%$ of the respondents have an education equal to or higher than the bachelor's Degree or similar. This imbalance does not create results that are excessively distorted 
Table 2. Characteristics of respondents

\begin{tabular}{|c|c|c|c|}
\hline Variable & Description & No of respondents & $(n=159)$ Percentage \\
\hline \multirow{2}{*}{ Gender } & Male & 83 & $52.2 \%$ \\
\hline & Female & 76 & $47.8 \%$ \\
\hline \multirow{5}{*}{ Age } & $18-25$ & 49 & $30.8 \%$ \\
\hline & $26-35$ & 43 & $27.0 \%$ \\
\hline & $36-50$ & 28 & $17.6 \%$ \\
\hline & $51-60$ & 19 & $11.9 \%$ \\
\hline & Over 60 & 20 & $12.6 \%$ \\
\hline \multirow{4}{*}{ Level of education } & High school Degree or lower & 19 & $12.0 \%$ \\
\hline & Bachelor's Degree or similar & 58 & $36.5 \%$ \\
\hline & Master's Degree or similar & 60 & $37.7 \%$ \\
\hline & $\mathrm{PhD}$ or similar & 22 & $13.8 \%$ \\
\hline
\end{tabular}

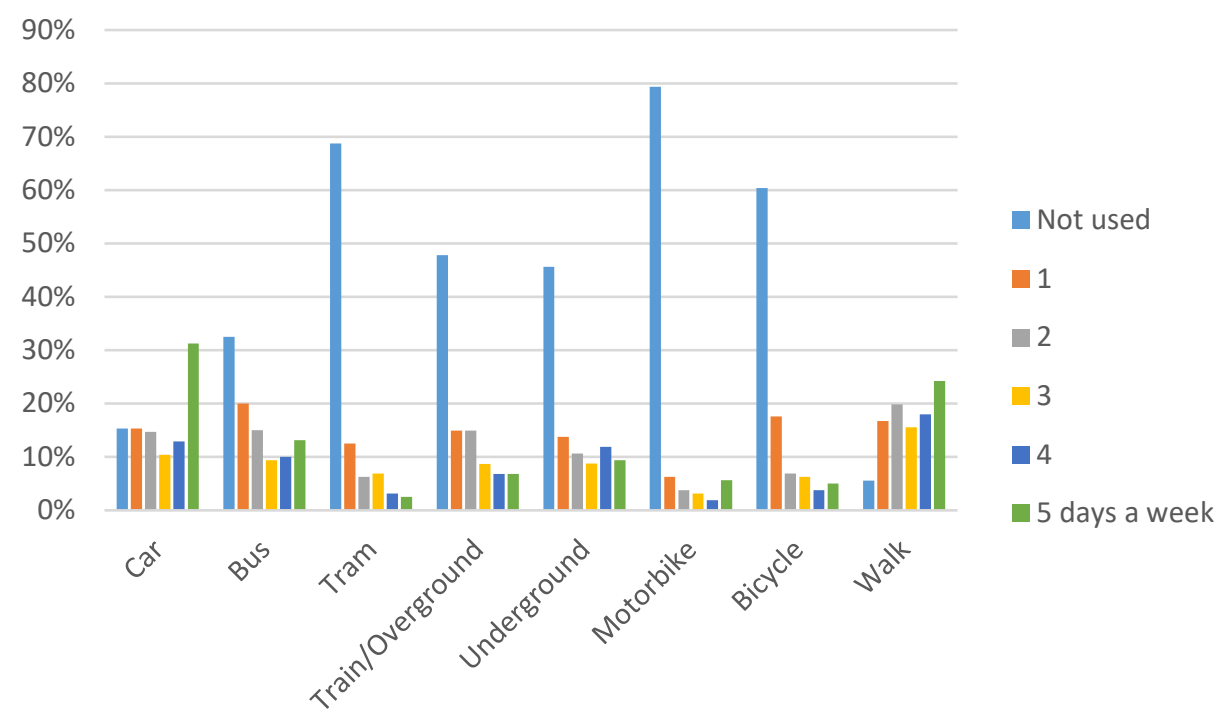

Figure 1. Mode split

by the real market conditions of electric mobility. As described by Axsen et al. (2009), individuals who buy a new vehicle and who are informed about new technologies have an income and education slightly higher than the average of the population. Furthermore, the analysis shows that $58 \%$ of respondents are under 35 .

The mode choice analysis, shown in Figure 1, reflects Italians mobility habits (Carrese et al., 2015). In fact, $31 \%$ use gasoline or diesel cars to reach the work place five days a week, and only $15 \%$ never do. Furthermore, $85 \%$ own at least one standard gasoline car for every two household members. This observation raises interest towards the Italian sustainable mobility that, as already mentioned, is affected by a lack of adequate policies and incentives. Furthermore, the cultural heritage of the private car as a status symbol is still well established. Zhao et al. (2015) define carpride as "the cognitive evaluation of, and emotional response to, the positive self-representation elicited by car ideation". In their work, the authors do not specify what kind of vehicle they are referring to, although readers may likely think about standard gasoline/diesel vehicles. Thus, the main issue that this work addresses is the definition of the variables and the aspects that most characterize users' propensity towards electric mobility or, in other words, what can constitute the e-carpride.

A multivariate analysis allows us to identify a group of various attributes as new variables that have similar ratings. The analysis was conducted using the Varimax method for orthogonal rotation, which maximizes the sum of the variance of the factor loadings. At the end of the process, an interpretation of the obtained factors was necessary.

In this analysis it was necessary to define the input variables. Initially, there were 116 variables given by the 33 questions and by its sub devices; after data cleaning 59 representative variables were defined. In this study, the statistical software SPSS, was used. Following an iterative process with the defined 59 variables, the data quality was confirmed with a value of 0.646 for the KMO test (Kaiser-Meyer-Olkin).

Based on screen analysis, the variables were grouped into four factors: (1) Costs, (2) Alternative fuels, (3) Charger unit \& Investment \& Climate Changes and (4) Characteristics of the vehicle. These represent respectively 14.1\%, 8.9\%, $5.9 \%$ and $5.3 \%$ of the variance. The factor names were defined by analyzing the "Rotated Components Matrix". The set of 59 variables was analyzed with the purpose of accepting those with the same degree of satisfaction or comparison (Kim et al., 2015). At the end of this phase, the non-representative variables of the phenomenon were 
European Journal of Sustainable Development Research, 2(3), 32

Table 3. Factor loading of eMobilita project

\begin{tabular}{|c|c|c|c|c|}
\hline \multirow{2}{*}{$\begin{array}{l}\text { Importance of variables related to electric urban } \\
\text { Mobility }\end{array}$} & \multicolumn{4}{|c|}{ Factor } \\
\hline & 1 & 2 & 3 & 4 \\
\hline \multicolumn{5}{|l|}{ Factor 1: Costs $(14.1 \%$ of variance, $\lambda=8.3)$} \\
\hline Fuel consumption & $\underline{0.767}$ & 0.062 & 0.225 & 0.045 \\
\hline Cost (Maintenance / Resale value / Taxes / Insurance, etc.) & $\overline{\mathbf{0 . 7 0 7}}$ & 0.180 & 0.025 & -0.038 \\
\hline Cost of vehicle maintenance & $\underline{0.694}$ & 0.173 & 0.249 & 0.096 \\
\hline Cost of retention (Insurance / Travel tax / Luxury tax) & 0.694 & 0.154 & 0.165 & 0.008 \\
\hline Vehicle purchase price & $\overline{0.682}$ & 0.329 & -0.096 & -0.119 \\
\hline \multicolumn{5}{|l|}{ Factor 2: Alternative fuels (8.9\% of variance, $\lambda=5.3)$} \\
\hline Bioethanol & 0.038 & $\underline{0.708}$ & -0.010 & -0.058 \\
\hline Biofuel & 0.020 & $\underline{0.701}$ & -0.097 & 0.050 \\
\hline Biofuel powered machines & 0.127 & $\overline{0.612}$ & 0.150 & 0.114 \\
\hline \multicolumn{5}{|c|}{ Factor 3: Charger unit \& Investment \& Climate Changes (5.9\% of variance, $\lambda=3.5$ ) } \\
\hline Electric buses for reduce pollution & 0.198 & 0.097 & $\underline{0.572}$ & 0.217 \\
\hline Climate change affects daily choices & 0.189 & 0.093 & $\underline{0.568}$ & -0.075 \\
\hline Shopping malls invest in charging units & 0.141 & 0.247 & $\overline{0.562}$ & 0.039 \\
\hline Return of the electric vehicle investment in 10 years & -0.013 & 0.211 & $\overline{0.562}$ & -0.211 \\
\hline Electric vehicles for reduce pollution & 0.088 & 0.062 & $\overline{0.527}$ & 0.337 \\
\hline State provides to installing rapid charger units & 0.134 & 0.187 & $\overline{0.518}$ & 0.111 \\
\hline Restricted areas for internal combustion vehicles & 0.137 & -0.198 & 0.509 & -0.245 \\
\hline Municipality invests in charging units & 0.215 & 0.324 & $\underline{0.503}$ & 0.135 \\
\hline \multicolumn{5}{|l|}{ Factor $4:$ Characteristics of the vehicle (5.3\% of variance, $\lambda=3.1$ ) } \\
\hline Technology & 0.289 & -0.124 & 0.179 & $\underline{0.649}$ \\
\hline Engine / Speed / Performance & 0.244 & -0.113 & -0.044 & $\underline{0.621}$ \\
\hline Model & 0.029 & -0.054 & -0.374 & $\overline{\overline{0.609}}$ \\
\hline
\end{tabular}

removed, obtaining 20 variables (Table 3). The factors were named with the scope of representing as much as possible the characteristics of the variables identified.

From the results, it is interesting to learn that Factor 2 (Alternative fuels) is an important item for the integration of electric urban mobility. This conclusion is in line with the claims of European associations, such as the European renewable ethanol association, which states that if Europe wants to achieve the ambitious results of decarbonizing European transport, it is necessary to adopt realistic solutions, such as low-emission mobility. In fact, they propose, in addition to the diffusion of electric cars, the use of vehicles powered by fuels with low environmental impact such as ethanol (ePure, 2017).

The purpose of this analysis is to define a set of factors, consisting of groups of questions, which are able to describe the diffusion of sustainable mobility in urban areas. Although it is not a real psychometric factorial analysis, the survey carried out on an exclusively Italian sample has provided the essential elements for the design of a synthetic questionnaire, focused on defining users who are inclined to electric mobility.

Finally, respondents were asked explicitly about their willingness to buy an electric vehicle, still assuming that the results obtained are representative of the phenomenon. In the short term (1-2 years), $13 \%$ of respondents are interested in purchasing an electric vehicle. In the 3-5-years scenario, this percentage stands at $30 \%$. In particular, in relation to the initial scenario, the Italian issue obtained an increase of almost $200 \%$.

\section{CONCLUSIONS AND FUTURE DEVELOPMENTS}

Responses from an Italian sample of 159 respondents have shown that there is currently a widespread lack of knowledge regarding the recent technological progress concerning electric mobility, most likely due to poor communication at institutional, corporate, and political level. In particular, it has been observed that the statistical sample is unaware of the real potentiality of electric vehicles in terms of charging times and charging infrastructure currently available in Europe. If the Italian case is specifically analyzed, electric mobility is not sufficiently treated by institutions and is not properly incentivized for consumers. As a matter of fact, this is translated into low sales compared to other European states. For instance, in 2016 only 1,400 BEVs were registered in Italy, while in 2015 17,650 BEVs were registered in France, the country that recorded the highest number of BEVs registrations (EEA, 2016). This low result is due to past Italian policies that encouraged, through particular incentives, the purchase of LPG and methane vehicles. The preliminary results of our research show that today's market is no longer interested in these old technologies, yet supports hydrogen, biofuels and electric vehicles. Furthermore, the present sample that uses daily GPL/methane vehicles is smaller than the electric/ hybrid vehicles. This trend is confirmed by the adaptation of automotive manufacturers to drivers' demands, resulting in a growing variety of models, reduced battery costs (achieved through economies of scale), and increased autonomy of BEVs. 
Regarding the issue of government support, the importance of subsidies in purchasing and enhancing the infrastructure for electric mobility is repeatedly confirmed. From this analysis, it is clear that Italy should intervene, for example by taking hints from Norway's policy, world leader in the use of electric vehicles (EEA, 2016). Indeed, at the moment the Italian policy provides benefits only on car (road) tax, making it necessary to rely on regional or municipal measures for further benefits.

The authors provide an updated overview of the Italian situation in terms of electric mobility, with the aim of extending the study at European level. The study describes the environmental concerns, such as climate change and different types of pollution that affect the daily choices and behavior of respondents. The researchers have confirmed several times the influence of sustainable mobility for the reduction of pollution. At this stage, the perception and propensity of "Citizens" respondents were described, with the possibility for future analysis of other types of respondents, such as "Industries" and "Public Authorities", in order to provide a better overview of users. Moreover, in the short-medium term, it would be interesting to study the incidence of the factors obtained from the analysis, in particular the one concerning "alternative fuels". Indeed, the study has shown that at this early stage, these factors can contribute to the behavioral change of users who are adverse to electric mobility. Furthermore, future comparative analysis of the results obtained by various researchers ultimately form a single database and offer an overview at a European level.

\section{ACKNOWLEDGEMENTS}

This research has been carried out as part of the European project Marie Skłodowska-Curie (MSCA) Program for Research and Innovation - Horizon 2020. The MSCA-RISE action project is published with the proposal number 734459 and the following title: H2020-MSCA-RISE-2016 eMobilita, Electromobility in Urban Transport: A Multi-Dimensional Innovation (Socio-Economics and Environmental Effects).

\section{REFERENCES}

André, M., Keller, M., Sjödin, Å., Gadrat, M., McCrae, I. and Dilara, P. (2009). The Artemis European tools for estimating the transport pollutant emissions. 18th Annual International Emission Inventory Conference. Baltimore, Maryland, USA.

Asdrubali, F., Baldinelli, G., D’Alessandro, F. and Scrucca, F. (2015). Life Cycle Assessment of electricity production from renewable energies: review and results harmonization. Renewable and Sustainable Energy Reviens, 42, 1113-1122. https:// doi.org/10.1016/j.rser.2014.10.082

Axsen, J. and Kurani, K. S. (2013). Hybrid, plug-in hybrid, or electric-What do car buyers want? Energy Policy, 61, 532-543. https://doi.org/10.1016/j.enpol.2013.05.122

Axsen, J., Mountain, D. C. and Jaccard, M. (2009) Combining stated and revealed choice research to simulatethe neighbor effect: The case of hybrid-electric vehicles. Resource and Energy Economics, 31, 221-238. https://doi.org/10.1016/j.reseneeco.2009.02.001

Bateman, I. J., Carson, R. T., et al. (2002). Economic Valuation with Stated Preference Techniques: A Manual. Edward Elgar, Cheltenham/Northampton. https:/ / doi.org/10.4337/9781781009727

Beltran, B., Carrese, S., Cipriani, E. and Petrelli, M. (2009). Transit network design with allocation of green vehicles: A genetic algorithm approach. Transportation Research Part C, 475-483.

Burgess, M., King, N., Harris, M. and Lewis, E. (2013). Electric vehicle drivers reported interactions with the public: Driving stereotype change? Transportation Research Part F: Traffic Psychology and Behaviour, 17, 33-44. https:// doi.org/10.1016/j.trf.2012.09.003

Carrese, S., Nigro, M. and Patella, S. M. (2015). Analysis of the demand for an electronic advise of traffic code violations. In: 2015 International Conference on Models and Technologies for Intelligent Transportation Systems (MT-ITS). Budapest, June 2015, p. 402-407, ISBN/ISSN: 978-963-313-142-8. https://doi.org/10.1109/MTITS.2015.7223286

Carrese, S., Giacchetti, T., Patella, S. M. and Petrelli, M. (2017). Real time ridesharing: understanding user behavior and policies impact. Carpooling service case study in Lazio Region, Italy. 5th IEEE International Conference on Models and Technologies for Intelligent Transportation Systems (MT-ITS), Naples, Italy, 721-726.

Carrese, S. and La Spada, S. (2013). Urban Electric Mobility Impacts on Road Pollutant Emissions: The Role of ITS \& Traffic Management Solutions. 20th ITS World Congress, Tokyo, Japan.

Dijk, M., Orsato, R. J. and Kemp, R. (2013). The emergence of an electric mobility trajectory. Energy Policy, 52, 135145. https://doi.org/10.1016/j.enpol.2012.04.024 
EEA-European Environment Agency (2016). Electric vehicles in Europe. Available at: http:/ / espas.eu/orbis/sites/default/files/generated/document/en/Electricvehicles2016_THAL16019ENN.pdf

Eideh, O. A. (2017). Idrogeno, è alleanza tra multinazionali su tecnologia e prodotti. Si muove qualcosa anche in Italia. Available at: https://www.ilfattoquotidiano.it/2017/01/23/idrogeno-e-alleanza-tra-multinazionali-sutecnologia-e-prodotti-si-muove-qualcosa-anche-in-italia/3334176

ePure-European renewable ethanol. (2017). More ambition needed to decarbonise EU transport. Available at: http:/ / epure.org/media/1505/170126-more-ambition-needed-to-decarbonise-eu-transport-politico-event.pdf

European Alternative Fuels Observatory, Fuels \& Vehicles (2017). Available at: http://www.eafo.eu

EVUE-Electric Vehicles in Urban Europe. (2015). Available at: http://urbact.eu/sites/default/files/import/Projects/EVUE/documents_media/EVUE_report_280912_FI NAL.pdf

Hunecke, M., Blöbaum, A., Matthies, E. and Höger, R. (2001). Responsibility and Environment: Ecological Norm Orientation and External Factors in the Domain of Travel Mode Choice Behavior. Environment and Behavior, 33, 830-852. https:/ / doi.org/10.1177/00139160121973269

IEA-International Energy Agency. (2016). Beyond one million electric cars. Available at: http://selectra.ie/sites/default/files/pdf/Global_EV_Outlook_2016.pdf

Kim, D., Ko, J. and Park, Y. (2015). Factors affecting electric vehicle sharing program participants attitudes about car ownership and program participation. Transportation Research Part D: Transport and Environment, 36, 96-106. https://doi.org/10.1016/j.trd.2015.02.009

Leurent, F. and Windisch, E. (2011). Triggering the development of electric mobility: a review of public policies. European Transport Research Review, 3, 221-235. https://doi.org/10.1007/s12544-011-0064-3

Massiani, J. (2015). Cost-Benefit Analysis of policies for the development of electric vehicles in Germany: Methods and results. Transport Policy, 38, 19-26. https://doi.org/10.1016/j.tranpol.2014.10.005

Mock, P., Hülsebusch, D., Ungethüm, J. and Schmid, S. A. (2009). Electric vehicles - A model based assessment of future market prospects and environmental impacts. EVS24 International Battery, Hybrid and Fuel Cell Electric Vebicle Symposium. Stavanger, Norway.

Saunders, C. D. (2003). The Emerging Field of Conservation Psychology. Human Ecology Review, 10(2), 137-149.

Stern, P. C. (2005). Understanding individuals' environmentally significant behavior. Environmental Law Reporter News and Analysis, 35(11), 10785.

Transport \& Environment (2016). Electric Vehicles in Europe. Available at: https://www.transportenvironment.org/sites/te/files/publications/TE\%20EV\%20Report \%202016\%20FIN AL.pdf

Zhao, Z. and Zhao, J. (2015). Car pride: Psychological structure and behavioral implications. 94th Annual Meeting of the Transportation Research Board, W ashington, DC. 